\title{
The Effects of Teenage Pregnancy on the Educational Attainment of Girls at Chorkor, a Suburb of Accra
}

\author{
Charles Gyan
}

Department of Social Work University of Ghana

\section{Doi:10.5901/jesr.2013.v4n3p53}

\begin{abstract}
Recently, the incidence of teenage pregnancy has been very high in Ghana. The study therefore was designed to explore the effects of teenage pregnancy on the educational attainment of the girl-child at Chorkor. A total sample size of fifty-five (55) respondents was used for the study. Questionnaire, in-depth interview, focus group discussions and observation were used to collect data for the study. With respect to factors that lead to teenage pregnancy, it was evident that poor parenting, poverty and peer influence are the major causes of teenage pregnancy. The study also revealed that most of the teenage mothers drop out of school. The study therefore recommended that teenage mothers should be helped in their psychosocial development and job skills development.
\end{abstract}

Keywords: Teenage pregnancy, educational attainment, girl-child education, pregnancy

\section{Introduction}

One major contemporary social problem confronting most countries in the world is Teenage pregnancy. From the first world countries such as the United states to the third world countries, this problem has been a source of worry for policy makers, social workers and other human service providers due to its negative repercussions on the girl-child (Grunseit, 2007).

In 1997, Grunseit found that the USA had the highest rate of adolescent pregnancy. In addition, he stated that every year more teenage girls become pregnant, many younger than 17 years old. Xinhua (1996) also reported that in Ghana, nearly $33.4 \%$ of recorded childbirths occurred to teenagers between ages thirteen (13) and nineteen (19). This report was based on childbirths that were reported in public hospitals. The situation is worse in the rural areas where traditional birth attendants are used and no statistical records are kept. More disheartening is a report from Xinhua (1996) that one out of three girls aged 15 to 19 residing in the central region of Ghana has had a child.

Most authors have linked poverty to teenage pregnancy and its subsequent motherhood. They see poverty as a cause at the same time an effect of teenage pregnancy. For instance, Keller, Hilton \& Twumasi-Ankrah (1999) opined that in rural communities, family financial exigencies and social custom induce girls to stay out of school and enter into early sexual relationships which lead them into getting pregnant at early stages of their lives thereby making them continue to be in the cycle of poverty. This presupposes that tackling teenage pregnancy would have a trickling down effects on poverty and vice-versa.

Teenage pregnancy is one of the social ills that affect society. The existence of teenage pregnancy do not auger well for the development of the girl-child. This is attributable to the girls' age and the absence of any consistent means of support to care for the children and themselves when they should have been in school. It is alleged that teenage pregnancy and its associated motherhood are characterized with shame, disgrace, school dropout and sometimes end of the individual's dreams of achieving higher pursuits. According to Yampolskaya, Brown, and Greenbaum (2002), "...approximately $60 \%$ of adolescent mothers live in poverty at the time of the birth of their babies, and approximately $73 \%$ go on welfare within 5 years of giving birth."(p8)

Cunningham and Boult (1996) asserted that teenage pregnancy has a lot of social consequences which include school drop-out or interrupted schooling, falling prey to criminal activity, abortion, ostracism, child neglect, school adjustment difficulties for their children, adoption, lack of social security, poverty, repeated pregnancy and negative effects on domestic life.

It is suggested that school drop-out is a "uniquely predictive factor" of teenage pregnancy and a precursor to, rather than a consequence of, becoming pregnant (Bonell et al, 2004). Difficulties with school are accounted for in three 
inter-linked ways: firstly a strong dislike of school that leads to truancy, dropping out or formal exclusion (Hosie, 2007), secondly a lack of educational attainment (Hobcraft \& Kiernan, 1999), and thirdly low aspirations and expectations of the education system as being relevant for their future employment (Luker, 1996).

Hosie (2007) also found out that bullying by teachers or other students that were instrumental in their dislike of school. Those students whose attendance are poor and who dislike school prior to pregnancy have a negative attitude from their schools on disclosure of their condition and are less likely to remain in school than those who had good attendance beforehand (Hosie, 2007). The extensive literature review by Dilworth (2000) suggested that statistically, young mothers face a life of poverty, have lower levels of education and have less opportunity in the workplace than nonparenting teens. She found that research on teen pregnancy prevention usually focuses on the negative aspects of being a teen parent. It is also alleged that the relationship between teenage pregnancy and education goes in both directions. Teenagers who become pregnant are more likely to drop out of school and teenagers who drop out of school are more likely to become pregnant. It is against this background that this study seeks to explore the effects of teenage pregnancy on the educational attainment of the girl-child at Chorkor, a suburb of Accra.

\section{Purpose and Objectives}

The general purpose of this study was to find out the effect of teenage pregnancy on the education of the girl-child. The study specifically aimed to:

a. Identify the factors that lead to teenage pregnancy

b. Determine the effects of teenage pregnancy on educational opportunities for teenage girls.

\section{Methodology}

The study was carried out at Chorkor in the Greater Accra Region of Ghana. Chorkor is a fishing village and a neighborhood in the city of Accra. It had a population of 45,379 as of 2002 (Ghana Statistical Service, 2002). Chorkor is a low-income, densely populated community. Ga-Dangme is the largest ethnic group in Chorkor, followed by Akan (Owusu \& Agyei-Mensah, 2010). Chorkor has electricity, water pipes, schools, and clinics, but it lacks a drainage system and a good sanitary condition. The population for the study comprised all females and opinion leaders in Chorkor (both men and women).

Purposive and snowball sampling procedures were used in selecting respondents for the study. The purposive sampling technique helped to purposefully select respondents who can really provide the needed information for the study. After purposefully selecting and interviewing the initial subject, the researcher used the snowball sampling procedure to ask for assistance from the subject to help identify people with a similar trait of interest. The researcher then observed the nominated subjects and continued in the same way until fifty (50) respondents were interviewed.

Two focus group discussions were organized with each comprising five members (teenage mothers or girls). There were in-depth interviews with five teenage mothers and two key informants using unstructured interview schedule. The five (5) key informants were the head teachers of two selected schools in the community and three (3) opinion leaders in the community. Questionnaire was the major tool employed to collect quantitative data for the study. The questionnaire was administered in a face-to-face interview. Interview guide and observation were used to collect the qualitative data.

The qualitative data collected from the field were transcribed that is, they were typed (from interviews, and observational notes) into word processing documents. The researcher then carefully read the transcribed data, line by line, and divided the data into meaningful analytical units (that is segmenting the data). When meaningful segments were located they were coded. The coding was done by marking the segments of data with symbols, descriptive words, or category names.

During coding, the researcher kept a master list (that is a list of all the codes that were developed and used in the study). After coding, the data were thematically analyzed according to the objectives of the study.

The quantitative data on the other hand were edited coded and fed into the computer using the Statistical Packages for Social Sciences (SPSS). The data were analyzed using descriptive statistics. Tabular presentations of information were used to facilitate easy interpretation and comprehension.

\section{Results and Discussions}




\subsection{The Causes of Teenage Pregnancy by Respondents}

The researcher sought to find out the major factors that lead to teenage pregnancy. The responses of the respondents are presented statistically in table 1 below:

Table 1: Causes of Teenage Pregnancy

\begin{tabular}{lllllllll}
\hline Factors & \multicolumn{2}{c}{ Strongly Disagree } & \multicolumn{2}{c}{ Disagree } & \multicolumn{2}{c}{ Agree } & \multicolumn{2}{c}{ Strongly Agree } \\
& Freq. & $\%$ & Freq. & $\%$ & Freq & & Freq. & $\%$ \\
\hline Poor parenting & 0 & 0 & 5 & 10.0 & 18 & 36.0 & 27 & 54 \\
Love Seeking & 46 & 92.0 & 2 & 4.0 & 2 & 4.0 & 0 & 0 \\
Poverty & 1 & 2.0 & 1 & 2.0 & 3 & 6.0 & 44 & 88.0 \\
Peer Pressure & 11 & 22.0 & 2 & 4.0 & 30 & 60.0 & 7 & 14.0 \\
Media & 3 & 6.0 & 32 & 64.0 & 5 & 10.0 & 10 & 20.0 \\
Dropout & 4 & 8.0 & 13 & 26.0 & 6 & 12.0 & 27 & 54.0 \\
\hline
\end{tabular}

The researcher tried to find out the factors that cause teenage pregnancy and from table 1 above, poor parenting, poverty, media, peer pressure, school dropout and poverty were the major factors respondents attributed their plight to.

According to table $1,27(54 \%)$ of the respondents strongly agree to the fact that poor parenting can lead to teenage pregnancy, $18(36 \%)$ respondents agree while only $5(10 \%)$ respondents disagree. Parenting skills and parental attitudes have great implications on the lives and attitudes of children as portrayed by the attachment theory by Bowlby and the Social learning theories.

It is often argued that domestic violence and lack of love from parents for their wards most often than not force teenage girls seek for that love from their colleague males thereby resulting in early sex and its associated teenage pregnancies. In the researcher's quest to investigate this, the researcher asked the respondents to indicate whether love seeking can lead to teenage pregnancy and from table 1 it was evident that overwhelming majority of the respondents that is $48(96 \%)$ respondents strongly disagree to the assertion that love seeking can cause teenage pregnancy and the remaining 2 (4\%) respondents agree to the assertion.

Another factor worth exploring is the relationship between poverty and teenage pregnancy. Majority of the respondents that is $94 \%$ either agree or strongly agree to the fact that poverty can lead to teenage pregnancy.

It was evident that $37(74 \%)$ respondents agree or strongly agree that peer pressure is a major cause of teenage pregnancy while cumulatively, $13(26 \%)$ respondents disagree or strongly disagree to this assertion. With respect to the media's influence on teenage pregnancy, 32(64\%) respondents stated that they disagree, 3(6\%) respondents strongly disagree while 15(30\%) agree to the fact that the media have a greater impact on the high rate of teenage pregnancy in Ghana. This implies that the media has no significant influence on the prevalent rate of teenage pregnancy in the Chorkor community.

Finally, the major issue of great concern is school dropout and how it pushes teenagers into early sexual activities. It has been argued by several authors that school dropout is a cause as well as an effect of teenage pregnancy. That is girls who dropout of school are more likely to engage in early sexual activities thereby resulting in teenage pregnancy and also girls who become pregnant at early ages are more likely to drop out of school. In this study the researcher sought to find out whether respondents agree to the assertion that teenage pregnancy can be caused by school dropout. From Table 1 above it evidently clear that $66 \%$ of the respondents agree to this while $34 \%$ disagree.

\subsection{Effects of Teenage Pregnancy on Education}

The researcher asked the respondents to indicate whether they were still in school during the period of the study and their responses are presented in table 2 below:

Table 2: Whether the Respondent was in School 


\begin{tabular}{c|cc}
\hline Variable & Freq & Percent \\
\hline Yes & 7 & 14 \\
No & 43 & 86 \\
Total & $\mathbf{5 0}$ & 100 \\
\hline
\end{tabular}

From table 2 above, it is clear that an overwhelming majority that is a total of $86 \%$ of the respondents stated that they were not in school whiles $14 \%$ of the respondents indicated that they were in school. This implies that teenage pregnancy can be a cause as well as an effect of school dropout. That is being in school most often prevent teenagers from getting pregnant so those who have dropped out of school are likely to fall prey to teenage pregnancy.

Table 3: Number of hours respondents study before pregnancy * Number of Hours Respondents study after pregnancy Crosstabulation

\begin{tabular}{|c|c|c|c|c|c|}
\hline & \multirow{2}{*}{} & \multicolumn{2}{|c|}{ Number of Hours Respondents study after pregnancy } & \multirow{2}{*}{ Total } \\
\cline { 3 - 5 } & & Less than 1 & $1-2$ & $3-4$ & \\
\hline \multirow{3}{*}{ Number of hours respondents than 1 } & $1-2$ & 4 & 1 & 0 & 5 \\
study before pregnancy & $3-4$ & 2 & 5 & 1 & 8 \\
& 5 Tond above & 1 & 2 & 3 & 14 \\
& & 16 & 5 & 2 & 8 \\
& & 13 & 6 & 35 \\
\hline
\end{tabular}

From table 3 above it is clear that before the pregnancy, five (5), eight (8), fourteen (14) and eight (8) respondents studied for less than one (1) hour, from one (1) to two(2) hours, three (3) to four (4) hours and five (5) and more hours respectively. After the pregnancy, it is evident that sixteen (16), thirteen (13) and six (6) respondents studied for less than one (1) hour, from one (1) to two (2) hours and three (3) to four (4) hours respectively. This implies that there was a reduction in the number of hours respondents study after the pregnancy due issues associated with the pregnancy.

Table 4: Respondents' Academic Performance Before the Pregnancy

\begin{tabular}{|l|c|c|}
\hline Academic performance & Frequency & Percent \\
\hline Excellent & 3 & 8.6 \\
Very Good & 6 & 16.1 \\
Good & 22 & 62.8 \\
Average & 4 & 11.5 \\
Total & 35 & 100.0 \\
\hline
\end{tabular}

Respondents were asked to indicate their academic performance before the pregnancy and it was revealed that majority of the respondents were academically good. From table 4 above, $22(62.8 \%)$ respondents indicated that their academic performance was good, $6(16.1 \%)$ respondents stated that their academic performance was very good while 4 (11.5\%) respondents stated average as their academic performance. Interestingly, only $3(8.6 \%)$ respondents opined that their performance was excellent before the pregnancy. This shows that the respondents were performing well before the pregnancy.

\subsection{Respondents' Academic Performance After the Pregnancy}


To be able to ascertain the effect of teenage pregnancy on academic performance of teenage pregnant girls, the researcher further asked the respondents to indicate their academic performance after their pregnancy. A majority of the respondents posited that their performance was below average. From the study $18(51.4 \%)$ respondents posited that their performance after the pregnancy was below average while $12(34.9 \%)$ respondents indicated that their performance was average. The remaining $5(14.2 \%)$ respondents asserted that their academic performance was average after the pregnancy. The response from the respondents gives an indication of a strong relationship between teenage pregnancy and the respondents' academic performance. These findings are statistically presented in table 5 below:

Table 5: Respondents' Academic Performance After the Pregnancy

\begin{tabular}{|l|c|c|}
\hline Academic performance & Frequency & Percent \\
\hline Good & 5 & 14.2 \\
Average & 12 & 34.9 \\
Below Average & 18 & 51.4 \\
Total & 35 & 100.0 \\
\hline
\end{tabular}

The respondents were further asked to state the ways through which teenage pregnancy affects academic performance and the respondents' responses are presented in table 6 below:

Table 6: Ways Through Which Teenage Pregnancy Affects Academic Performance

\begin{tabular}{l|cc}
\hline \multicolumn{1}{c|}{ Variable } & Frequency & Percentage \\
\hline Reduces number of average study period & 29 & 82.8 \\
Reduces Absorption rate & 6 & 17.2 \\
Total & 35 & 100.0 \\
\hline
\end{tabular}

From table 6 above, it is evident that reduction in the number of average study period and reduction in the absorption rate of teenage pregnant girls are the major ways through which teenage pregnancy affects academic performance. Twenty-nine (29) respondents representing $82.8 \%$ indicated that the pregnancy affected their academic performance through reduction in their study hours while the remaining six (6) representing $17.2 \%$ opined that their absorption rates reduced after the pregnancy.

Table 7 below indicates the respondents' view on whether there is the possibility for them to go back to school after delivery. From table 7, majority of the respondents that is $47(94 \%)$ respondents believe that there is no possibility of going back to school after they had delivered while interestingly only $3(6 \%)$ of the respondents stated that is possible for them to go back to school after delivery. This implies that most of the teenage pregnant girls and mothers were not aware of the fact that after delivery they can still go to school. These findings are statistically displayed on table 7 below:

Table 7. Whether there is the Possibility for Respondents to go Back to School after delivery

\begin{tabular}{|c|c|c|}
\hline Variables & Frequency & Percent \\
\hline Yes & 3 & 6.0 \\
No & 47 & 94.0 \\
Total & $\mathbf{5 0}$ & 100.0 \\
\hline
\end{tabular}

\section{Discussion of the Findings}

The purpose of this research was to explore the effects of teenage pregnancy on the educational attainment of teenage mothers. This section covers the discussion of the major findings revealed by the study based on the study objectives and in line with the literature in the second chapter of the study.

\subsection{Factors that Lead to Teenage Pregnancy}


With respect to factors that lead to teenage pregnancy, this study revealed that poor parenting is a major cause of teenage pregnancy. From table 1 (page 5) it was revealed that 90\%) of the respondents agree to the fact that poor parenting can lead to teenage pregnancy. This finding is consistent with Sarri \& Phillips' (2004) findings that parents play a pivotal role in curbing teenage pregnancy through proper parenting skills and parental attitudes.

Again, the study revealed that love seeking cannot lead to teenage pregnancy and from table 1 (page 5) it was evident that most of the respondents disagree to the assertion that love seeking can cause teenage pregnancy. The study revealed that most of the respondents live in "domestic violence-free homes" and had parents who showed them the needed love and care. These findings contradict Davies et al's (2004) findings that the relationship and atmosphere within the home can push teenagers to seek for love and affection from their male colleagues which invariably make them engage in early sex which consequently lead to teenage pregnancy.

Also, the study revealed that poverty was a major contributory factor to teenage pregnancy. Table 1 (page 5) shows that majority of the respondents, that is $94 \%$ agree to the fact that poverty pushed them into early sex. It was evident that material deprivation made most of them engaged in early sexual relationship for money and food which made them victims of teenage pregnancy. These findings support CSA's (2003) findings that most young women in poor families exchange sex for money or gifts.

Furthermore, it was evident from the study that peer influence contributes greatly to teenagers' involvement in early sex. From table 1 (page 5 ) it was clear that $74 \%$ of the respondents agree that peer pressure is a major cause of teenage pregnancy. Williams' (1991) assertion that most teenagers' reliance on their peers for information makes them fall prey to teenage pregnancy supports this finding. This finding is also consistent with the theory that guides this study in the sense that the teenagers learn a lot from their peers. That is peer influence as revealed by the study has greater impact on the behavior of teenagers. Interestingly the study revealed that the media had little or no influence on the incidence of teenage pregnancy. From the study it was clear that about $70 \%$ of the respondents disagree to the assertion that the media influence. This finding contradicts Hymowitz's (1997) findings that the mass media freely show sex on television and movies without displaying marital ties or good personal conduct. Instead sex looks easy, fun and glamorous. It often appears as if everyone is doing it (World Population Day Essays, 1996).

\subsection{The effects of teenage pregnancy on educational opportunities for teenage girls.}

It was revealed from the study that most of the teenage mothers had dropped out of school. From table 2 (page 7) about $86 \%$ of the respondents indicated that they had dropped out of school. School dropout is seen as a cause as well as a consequence of teenage pregnancy. It was clear from the study that some of the respondents dropped out of school due to the pregnancy while others became pregnant because they dropped out of school. These findings are consistent with the theory underpinning this study. Thus most pregnant girls drop out of school to deliver and after delivery feel shy and do not return to school thereby serving as a baseline for other girls with similar problems to imitate. These findings are also consistent with Muganda-Onyando \& Omondi's (2008) assertion that pregnancy acts as a catalyst to school dropout in poor families. O'Connor (1999) re-echoed tis by stating that academically- oriented females are less likely to give birth while still in high school.

Again, the study revealed that teenage pregnancy reduces the study hours of the respondents. From table 3 (page 8) it was clear that before the pregnancy, the respondents could study averagely for three (3) to four (4) but this reduced to an average of one (1) to two (2) hours. These findings support Mohase's (2006) findings that issues of pregnancy affect the level of concentration of pregnant women.

\section{Recommendations}

Based on the evidence obtained from the study, the following recommendations have been suggested to guide policy decisions that would help reduce the incidence of teenage pregnancy. Firstly, given the educational, social, economic, and employment histories common among teenage parents, career development is a priority for helping this group make the transition from adolescence to economic independence. These early parents are in special need of psychosocial development, life skills development, career awareness, and job skills development. Governments should prioritize the career development of teenage mothers.

Again, a number of psychosocial factors can affect the education and training of teen parents. These factors include low self-esteem; low aspirations, motivation, and expectations; unrealistic goals and ambitions; limited emotional resources for support and maintenance; and lack of role models. To help teen parents overcome the ramifications of their 
disadvantaged backgrounds, attention should be given to the building of their self-concept and support systems; learning how to meet the challenge of combining work and family roles; learning how to give and receive emotional support and enhancing interpersonal communication and relationships.

Also, in addressing teenage parenthood there should also be sex education and the provision of school-based day care and parenting centers for those teenagers who are already (or soon will be) parents. These strategies would provide viable and effective avenues for giving students a better chance to complete their education, while also offering training in responsible parenting.

Moreover, as stated earlier, pregnant teens who drop out of school have fewer opportunities for themselves, and their children are also less likely to succeed in school or careers. For this reason, it is important to support and encourage pregnant teens in getting their education. In addition to the formal education system, there are also some other options for pregnant teens in some areas: Special schools for pregnant or parent teens, programs to help pregnant teens finish school and non-formal education.

Furthermore, they also need someone to encourage them through the hard times and help them reach their goal. Parents, teachers, school counselors, social workers and peer support groups should provide them with the needed support to help them complete their education and skills development programs.

Finally, poverty was one major problem revealed by the study as a cause of teenage pregnancy. To address this, it is recommended that the government should strengthen families to be able to provide the needs of their members including adolescent girls.

In sum, it can be concluded from the study that teenage pregnancy affects the educational attainment of teenage girls. It is evident that there is no magic bullet for teenage pregnancy. Given the multiple levels of predisposing factors of teenage pregnancy, single intervention strategies by single sectors will not solve teenage pregnancy. What is required is a comprehensive approach that incorporates the home, the school, the community, the healthcare setting as well as change at the structural level.

\section{References}

Bonell C., Allen E., Strange V., Copas A., Oakley, A., Stephenson J., \& Johnson A. (2004). The effect of dislike of school on risk of teenage pregnancy: testing of hypotheses using longitudinal data from a randomized trial of sex education. Journal of Epidemiology and Community Health. 59(2), $223-230$.

Centre for the Study of Adolescence (CSA), (2003). The Status of Young people in Kenya; A Situation Analysis. Unpublished Survey Report.

Davies, S. L., DiClemente, R. J., Wingwood, G. M., Person, S. D., Crosby, R. A., Harrington, K. F. (2004). Relationship characteristics and sexual practices of African American adolescent girls who desire pregnancy. Health Education \& Behavior, 31(2), 85-96.

Ghana Statistical Service, (2002). 2000 Population and Housing Census of Ghana, Accra, Ghana: Ghana Statistical Service.

Grunseit, A. (1997). Impact of HIV and Sexual health education sexual behavior of young people: A review update. Geneva: UNAIDS.

Hobcraft, J. \& Kiernan, K. (1999). Childhood poverty, early motherhood and adult social exclusion. Centre for Analysis of Social Exclusion (CASE) paper Case 28 July 1999, London School of Economics.

Hosie, A.C.S. (2007). I hated everything about school" an examination of the relationship between dislike of school, teenage pregnancy and educational disengagement. Social Policy and Society. 6(3), 333 - 347.

Hymowitz, K. S. (1997). Lack of parental influence is a factor in teenage pregnancy. In S. P. Thompson (Ed.), Teenage pregnancy: Opposing viewpoints (pp. 82-92). San Diego, CA:Greenhaven Press.

Keller, T. E., Hilton, B. D. \& Twumasi-Ankrah, K. (1999). Teenage pregnancy and motherhood in Ghanaian Community. Journal of social Development in Africa, 14(1), 69 - 84.

Luker, K. (1996). Dubious conceptions. The politics of teenage pregnancy. U.S.A: First Harvard University Press.

Mohase, T. B. (2006). The influence of teenage pregnancy and parenting on the performance of soshanguve secondary schools learners. Thesis submitted in partial fulfillment of the requirements for the degree of Magister Technologiae: Educational Management at the Tshwane University of Technology.

Muganda-Onyando, R., \& Omondi, M. (2008). Down the Drain: Counting the Costs of Teenage Pregnancy and School Dropout in Kenya. Nairobi: Centre for the Study of Adolescence.

O'Connor, M. L. (1999). Academically oriented teenage women have reduced pregnancy risk. Family Planning Perspectives, 31(1), 105106.

Owusu, G \& Agyei-Mensah, S. (2010). A comparative study of ethinic residential segregation in Ghana's two largest cities, Accra and Kumasi.

Sarri, R., \& Phillips, A. (2004). Health and social services for pregnant and parenting high risk teens. Children \& Youth Services, 26(1), 537-560.

Williams, W. (1991). Black teenage mothers, Pregnancy and child bearing from all perspectives. RSA: Cape Town.

World Population Essay Day. (1996). RSA 
Xinhua News Agency, (1996). Teenage pregnancy high in Ghana's central region. Inronautics Electric Library, June 20.

Yampolskaya, S., Brown, E., \& Greenbaum , P. (2002). 'Early Pregnancy among Adolescent Females with Serious Emotional Disturbances: Risk Factors and Outcomes. Journal of Emotional and Behavioral Disorders. 10(2), 108 - 115. 